TITLE:

\title{
ON A SMALL COLLECTION OF ASCIDIANS FROM THE VICINITY OF NHATRANG, VIET NAM
}

AUTHOR(S):

Tokioka, Takasi

\section{CITATION:}

Tokioka, Takasi. ON A SMALL COLLECTION OF ASCIDIANS FROM THE VICINITY OF

NHATRANG, VIET NAM. PUBLICATIONS OF THE SETO MARINE BIOLOGICAL LABORATORY 1967, 14(5): 391-402

ISSUE DATE:

1967-01-25

URL:

http://hdl.handle.net/2433/175450

RIGHT: 


\title{
ON A SMALL COLLECTION OF ASCIDIANS FROM THE VICINITY OF NHATRANG, VIET NAM ${ }^{1)}$
}

\author{
TAKASI TOKIOKA
}

Seto Marine Biological Laboratory

With 5 Text-figures

I had a favour of examining about a dozen specimens of ascidians which were collected in the vicinity of Nhatrang and submitted to me for identification by Dr. TrAN NGOC LoI of the Oceanographic Institute of Nhatrang. The present material comprises the following six species:

1. Polyclinum vasculosum Pizon

2. Eudistoma laysani (SLuiter)

3. Eudistoma sp. aff. angolanum (MiGHAELSEN)

4. Ascidia pacifica n.sp.

5. Polyandrocarpa (Eusynstyela) latericius (SLUITER)

6. Herdmania momus (SAVIGNY).

It is useless to repeat the descriptions of well defined species, and of course it should be avoided to make only the descriptions of individuals. But actually, in many of the species from the tropical Pacific, especially the compound ascidians, the variability or the exact characteristics of respective species have not yet been shown clearly, and this makes the exact identification very difficult. The following descriptions and figures of five of the six species are, then, given in a hope to afford any criteria by which one may be able to distinguish these forms distinctly from their allied forms. The final taxonomical rank of some forms here treated is left for future investigations. Before going to the descriptions of species, I wish to express here may hearty thanks to Dr. Tran NGoc LoI for his kindness in giving me this chance of examining the specimens and in sending me the full data about those specimens.

\section{Polyclinum vasculosum PizoN}

(Text-fig. 1)

There are three specimens, Sp. Nos. 45929, 45930, and 45931.

1) Contributions from the Seto Marine Biological Laboratory, No. 462.

Publ. Seto Mar. Biol. Lab., XIV (5), 391-402, 1967. (Article 25) 
Sp. Nos. 45929 and 45930 were found on the keel of the institute boat and without any special colouration while they were alive. Sp. No. 45931 is a small oval colony (Fig. $1 \mathrm{~A}$ ), $15 \mathrm{~mm} \times 12 \mathrm{~mm}$ in extent and $6 \mathrm{~mm}$ thick, with a single common cloacal aperture of a $3 \mathrm{~mm}$ diameter situated eccentrically. The surface is even and smooth; fully exposed, but with a small amount of mud at some places. The colony attached

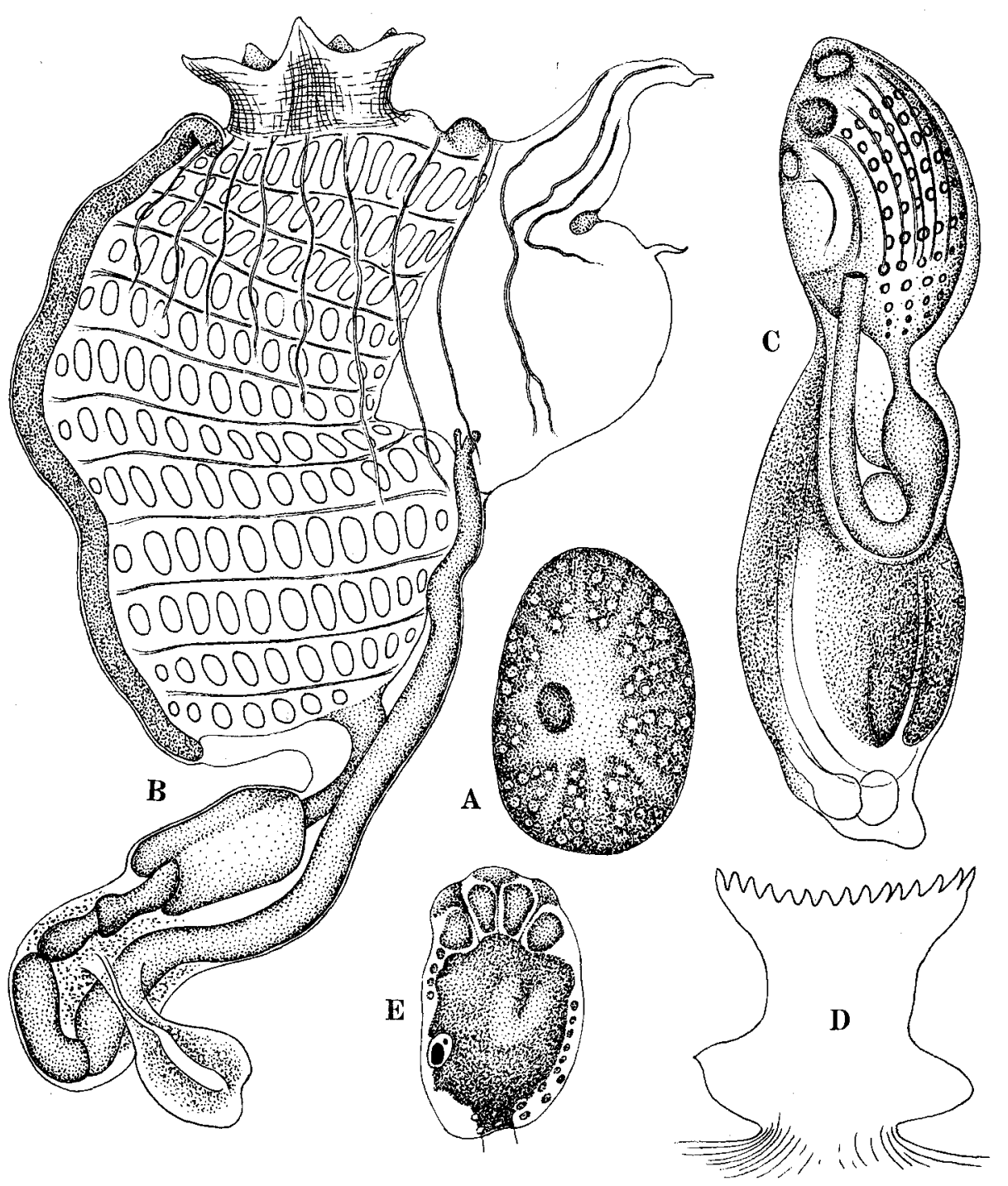

Fig. 1. Polyclinum vasculosum Przon. A-Sp. No. 45931, B-Left side of the zooid from the same colony, $\times 73$; C-Rudimentary zooid formed at the anterior end of an old abdomen, $\times 73$ : D-Short atrial languet with the pectinated distal edge, E-Right side of an embryo of advanced stage, $\times 73$. 
to the substratum by the whole underside. The test is soft, gelatinous, brownish in colour and translucent. Zooids are seen through the test; they are arranged roughly in groups which are separated from one another by about ten radial canals. Sp. No. 45930 is an oval flat mass, $35 \mathrm{~mm} \times 28 \mathrm{~mm}$ in extent and up to $9 \mathrm{~mm}$ in thickness, attached to the substratum by the whole underside. The surface is even, smooth, and free from any foreign matters. Common cloacal apertures are oval, each with about $1 \mathrm{~mm}$ diameter; some are fringed with minute tentacular processes along the margin. The test is soft, gelatinous, dark olive brown, and contains a number of minute vacuoles scattered in the superficial layer. Systems of zooids are scarcely discernible on the surface. Sp. No. 45929 is a flat colony, $49 \mathrm{~mm} \times 40 \mathrm{~mm}$ in extent and $9 \mathrm{~mm}$ thick, attached to the substratum by the whole underside. The common cloacal apertures are usually $1.5 \mathrm{~mm}-3 \mathrm{~mm}$ in diameter, though exceptionally attaining $6 \mathrm{~mm}$ across. The test is grayish brown and built similarly to Sp. No. 45930 . Zooids are embedded in the surface $2 \mathrm{~mm}$ (in Sp. No. 45931 ) to $4 \mathrm{~mm}$ (Sp. No. 45930) layer. Beneath the zooidal layer, the test becomes extremely soft. The thoracic stratum of the zooidal layer is penetrated with a well developed lacuna system. The abdominal stratum is made of soft but very sticky substance and thus the abdomens are taken out of the test with some difficulty. Thoraces are about $2 \mathrm{~mm}$ in a contracted state. The branchial aperture is distinctly 6-lobed. The atrial languet is long and ending in a simple tip in zooids from two larger colonies, but in the smallest colony it is short and with a pectinated distal edge (Fig. 1 D) in some zooids situated near the common cloacal aperture. A small but distinct prominence just posterior to the atrial aperture. Nine to eleven longitudinal muscles in the anterior half of the thorax on each side. Seven to nine are converging to the branchial aperture, while two, rarely three, are gathered to the atrial aperture. Transverse muscles are absent. Twelve (Sp. No. 45931) to fourteen (Sp. No. 45929 and 45930) stigmatal rows are present. In some zooids from larger colonies, the stigmatal rows may be 13 on the left and 14 on the right side. The number of stigmata in a row on each side is about 12 in smaller, but up to 25 in larger zooids near the middle of the branchial sac. The anus is bilobed and situated at the level of the seventh (in zooids with 12 stigmatal rows) to the eighth or ninth (in zooids with 13-14 stigmatal rows) transverse vessel. The transverse vessels are provided each with a series of papillae. The typical arrangement of tentacles is represented by the alternation of 6 large and 6 medium, intervened with 12 small ones. Some of the small tentacles are often missing. The ciliated groove is a small oval opening. The dorsal languets are displaced slightly to the left side from the dorso-median line, usually for the distance of two stigmata. Five to fifteen embryos in different stages of development were found in the incubatory pouch in zooids from the colony Sp. No. 45929.

Abdomens are about a half as long as the contracted thorax. The stomach is rather elongate, the hind-stomach and the middle intestine are defined distinctly. No zooids were found with the postabdomen including mature gonads. 
Embryos are ovoid, $480 \mu(460-490 \mu)$ in length and with the ratio of width/ length $0.59(0.56-0.62)$. Two pigment spots of the sensory organ are arranged obliquely antero-posteriorly. Four pairs of large ampullae at the anterior end of the body, besides a series of about a dozen follicular vesicles on the ventral and several ones on the dorsal side between the sensory organ and the dorsal attachment process. Attachment processes are arranged lineally.

Remarks: Although the exact appearance of the systems in larger specimens is obscure, it may probably be very similar to that of P. constellatum SAvigNY, because the zooids are provided with a very long atrial languet. As to the relations between the present species and $P$. constellatum and $P$. tsutsuii ToкіокA, refer the remarks given to $P$. vasculosum and $P$. constellatum in U.S. Nat. Mus. Bull. No. 251, 1967, pp. 51-56.

In the colony Sp. No. 45931, some elongate bodies of about $1.7 \mathrm{~mm}$ long were found embedded in the test. The specimen of such a body which is made transparent (Fig. $1 \mathrm{C}$ ) seems to show that it consists of the abdomen of an old zooid and the very young zooid newly built at the anterior end of the old abdomen. On the $500 \mu$ long rudimentary thorax, about 11 stigmatal rows and about eight longitudinal muscles are clearly discernible. It must be very interesting to learn the further behaviour of the old abdomen after the budding of the new zooid is completed.

\section{Eudistoma laysani (SLUITER)}

\section{(Text-fig. 2)}

A single colony (Sp. No. 46149) collected in the protected area at Cau Da on Nov. 8, 1965. The colony was found attached on the bamboo stick. It is $34 \mathrm{~mm} \times$ $18 \mathrm{~mm}$ in extent and $15 \mathrm{~mm}$ high, and consists of about 25 cormidia which are up to $11 \mathrm{~mm}$ long and with a $5 \mathrm{~mm}$ diameter. The basal portion of the colony common to those cormidia is covered with small tufts of fine algae and small nest tubes of polychaetes. Smaller cormidia contain each only a single or two zooids, but in larger cormidia up to 14 zooids are included. The test is soft, gelatinous, translucent and pale grayish brown; many faecal pellets are embedded in the basal portion of respective cormidia. Orange zooids are seen through the test. The structure of the test is rather loose and thus the zooids can be taken out of the test very easily. Zooids are up to $5.5 \mathrm{~mm}$ in length in a contracted state. Thoraces are 1.5 to $2.0 \mathrm{~mm}$ long. Both apertures are 6-lobed, siphons are distinct, but not long. About 20 longitudinal muscles on each side of the thorax, about 15 of which are converging to the branchial siphon, while other 5 to the atrial siphon. About 50 transverse muscles are running across the thoracal wall inside the longitudinal musculature. Fifteen to eighteen elongate stigmata in each of three rows on each side. Twelve large medium tentacles; some intervals, especially those on the ventral side, may include each a small tentacle. The ciliated groove is a small oval opening. Dorsal languets 
are displaced from the dorso-median line to the left side for the distance of a few stigmata. The anus is open at the second transverse vessel. Generally two embryos were found incubated on the right side of the thorax.

The abdomen is very elongate, the anterior half containing the oesophagus is slender. The stomach is about $800 \mu$ long, orange in colour, and situated apart from the posterior end of the abdomen for the distance of about one and a half times

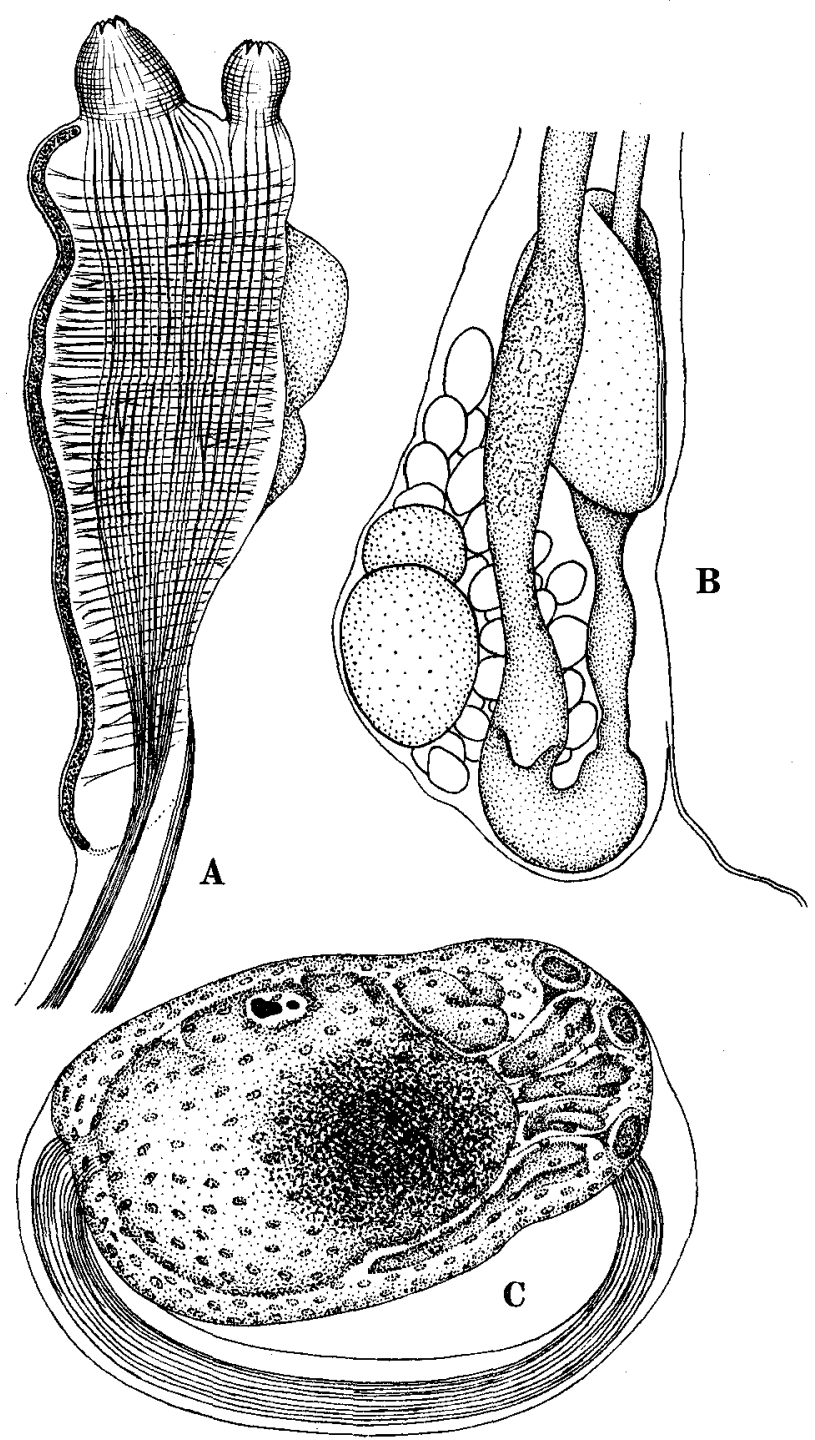

Fig. 2. Eudistoma laysani (SLUTTER). A-Left side of the thorax, $\mathrm{B}$ - Left side of the posterior half of the abdomen, $\mathrm{C}-\mathrm{Right}$ side of larva, $\times 73$. 
the stomach length. The hind-stomach is as long as the stomach. The middle intestine is thicker than the hind-stomach and occupies the posterior end of the intestinal loop. The junction between the middle intestine and the rectum is constricted slightly, but no coeca are formed there. The sharp colour change of the canal wall to orange in the rectum marks the boundary between the two portions distinctly. Up to 15 faecal pellets in the rectum. Circum-intestinal glands are found on the rectum at the level of the stomach. Gonads on the left side of the intestinal loop. Usually two mature ova and up to 60 testicular follicles are found there. A vascular vessel is issued from the dorso-posterior part of the abdomen, at the level of the junction between the hind-stomach and the middle intestine.

Embryo is about $820 \mu$ in length, the ratio of width/length is 0.61 . The body is yellow orange to reddish orange and the larval test is frothy, with a number of small whitish patches all over the surface. The pigment spots of the sensory organ are situated nearly at the middle of the body and arranged antero-posteriorly or obliquely dorso-ventrally. Probably four pairs of ampullae are present originally at the anterior end of the body. The common basal portion of the ventral pair is much extended posteriorly. Each of the pair between the middle and the ventral attachment processes may be splitted into two in advanced stages as seen in Fig. $2 \mathrm{C}$. The tip of respective ampullae becomes more or less lobated with the age. The middle attachment process is situated a little more apart from the ventral process than the dorsal one; this seems to show that the splitting of the ampullae between the middle and the ventral attachment processes might be a normal phenomenon.

Remarks: The appearance of the colony and the thoracic musculature of zooids are very similar in the present specimen and the colony from the Palau Islands which was examined by myself and described in U.S. Nat. Mus. Bull. 251. The difference found in the arrangement of the posterior ends of thoracic longitudinal muscles between these two colonies may be attributable to the state of the contraction. The structure of the ampullae in larvae from the present colony is rather unique. At present, it is quite unknown what this means. Further close observations are desirable to clarify this point.

\section{Eudistoma sp. aff. angolanum (MICHAELSEN)}

\section{(Text-fig. 3)}

There are four specimens, Sp. Nos. 45938, 45939, 45940, and 46411 in the material. Sp. Nos. 45938-45940 were found on June 9, 1965, attached to granite stones on the surf beaten coast of Hon Noi Island and they were blue or orange when alive. In all, nine colonies are included. The small four colonies of Sp. No. 46411 are $11 \mathrm{~mm} \times 4 \mathrm{~mm}$ to $15 \mathrm{~mm} \times 10 \mathrm{~mm}$ in extent and 6 to $8 \mathrm{~mm}$ in thickness and all with a simple outline. Colonies of other specimens are $24 \mathrm{~mm} \times 14 \mathrm{~mm}$ to $38 \mathrm{~mm}$ 
$\times 21 \mathrm{~mm}$ in extent and 8 to $12 \mathrm{~mm}$ in thickness. The $30 \mathrm{~mm} \times 17 \mathrm{~mm}$ colony of Sp. No. 45938 is of a very regular oval form (Fig. $3 \mathrm{~A}$ ) with up to $8.5 \mathrm{~mm}$ thickness and attached to the substratum by whole underside. The surface is even, smooth, and quite free from any foreign matters. Other four colonies of Sp. Nos. 45939 and 45940 are more or less lobated irregularly. The test is hard gelatinous, translucent, and dark grayish green to grayish blue, and the faintly greenish zooids are seen through. Zooids are distributed in the colony without forming any systems. The internal consistency of the test is rather sticky, but soft and zooids can be taken out of the test easily. Zooids are situated in the surface $2-4 \mathrm{~mm}$ thick layer; the thoracic
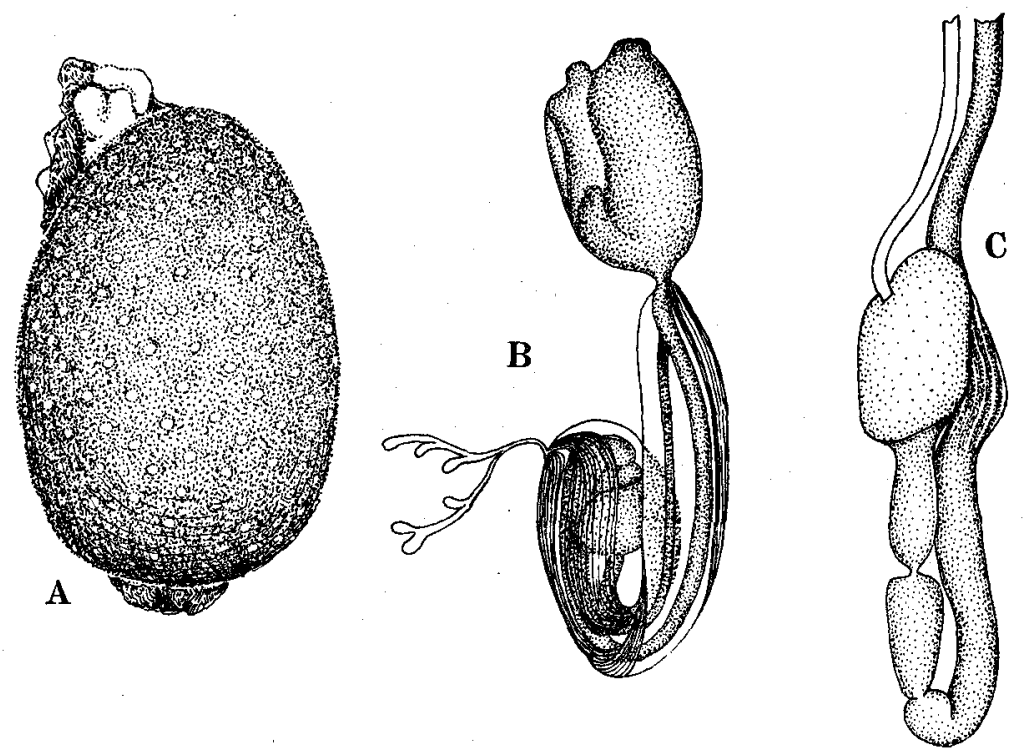

Fig. 3. Eudistoma sp. aff. angolanum (Mrahaelses). A-30 $\mathrm{mm}$ long by $17 \mathrm{~mm}$ wide colony (Sp. No. 45938), B-Right side of a laying zooid from the same colony, C-Posterior half of the intestinal loop of a considerably extended zooid from the same colony.

stratum is darker in colouration, because the pigments are deposited densely surrounding the thoraces. The bottom layer is paler and sparsely penetrated with vascular vessels, some of which may be filled with a series of faecal pellets. On the colony surface, branchial and atrial apertures of the strongly contracted zooids are defined as somewhat darker points. In addition to these, there are small dark greenish patches here and there.

Zooids are embedded in the test perpendicularly to the surface or laying in the very surface layer keeping the right side of the body to the colony surface. In the colony of Sp. No. 45938, many of zooids are laying, although the posterior portion of the abdomen is bent down towards the colony bottom (Fig. 3 B). In four small 
colonies of Sp. No. 46411 , zooids, which were mostly situated vertically, are all strongly contracted into the bottom layer, and the faecal pellets are found embedded near the bottom of the colony. Thoraces occupy about $1.5 \mathrm{~mm}$ of the body length attaining to $4 \mathrm{~mm}$ in a contracted state. Both apertures are 6-lobed. Twelve to fifteen rather stout longitudinal muscles on each side of the thorax, and a number of finer transverse muscles inside the longitudinal musculature. Because of strong contraction, it is very difficult to read the exact number of the transverse muscles, very probably they are 35 to 50. Ten to twelve stigmata in each of three rows on each side. Six large and six smaller tentacles alternate regularly. The smaller ones form the anterior tentacular ring, while the larger ones the posterior ring. The ciliated groove is represented by a small oval opening. The dorsal languets are situated on the left side approximately at the position of the third stigma from the dorso-median line.

The abdomen is markedly constricted off from the thorax. The neck, namely the anterior half of the abdomen anterior to the stomach, is rather thick (Fig. $3 \mathrm{~B}$ ), thin-walled, and with a pair of thick longitudinal muscle bands on the ventro-lateral wall and including the thin oesophagus and the thicker rectum inside. It is usually 1.5 2.0 times as long as the contracted throax. The posterior half of the abdomen, from the stomach to the rear end of the abdomen, is generally much contracted, although it attains to $2 \mathrm{~mm}$ in a relaxed state. In an extended state, the stomach is roughly oval and the hind-stomach is about 1.5 times the stomach length and with a remarkable constriction near the middle. In a strongly contracted state, the stomach is nearly spherical and the hind-stomach becomes very short. Mid-intestine was not defined clearly in examined zooids. The small part of the alimentary canal, occupying the posterior end of the loop, might be the mid-intestine. The circumintestinal gland consists of about 15 fine tubular structures arranged longitudinally on the rectum wall at the level of the stomach, where the rectum shows a rather sharp curve. The gonad is situated on the left side of the intestinal loop. The ovary occupies the centre of the gonad and the testicular follicles are up to 26 in examined zooids. The fully matured ovum may sometimes move to the posterior margin of the gonad.

Remarks: At first, the existence of many zooids laying in the very surface layer in some colonies tempted me to establish a new species for the present specimens. However, this feature does not seem to be of a definite singificance for a distinct species, because in some other colonies most zooids are situated perpendicularly to the colony surface. The structure of the test resembles superficially that of $E$. angolanum, but the test is quite devoid of any foreign matters embedded within it in the present specimens. The structure of zooids is similar to that of E. angolanum and also to that of E. sp. aff. angolanum from the Palau Islands described in U.S. Nat. Mus. Bull. 251, 1967, pp. 115-117. It is evident that the present specimens are included in the group comprising E. angolanum. But, the test of the present specimens which is not impregnated with foreign matters differs distinctly from that of angolanum. For these reasons, the present specimens are treated here provisionally as a species affined to 
E. angolanum, although this does not mean that the present specimens are exactly identical with $E$. sp. aff. angolanum reported from the Palau Islands; in the latter the test is dark brownish or dark purplish brown and a little harder in consistency at least in the abdominal stratum and bottom layer.

\section{Ascidia pacifica n. sp.}

(Text-fig. 4)

Ascidia sydneiensis-Tokioka (1950): Publ. Seto Mar. Biol. Lab., I(3), p. 133, text-fig. 12, Pl. 9 fig. 3. -(1952): Publ. Seto Mar. Biol. Lab., II(2), pp. 105-107, text-fig. 10.

Ascidia sydneiensis sydneiensis-TokıоKA (1953): Ascidians of Sagami Bay. pp. 223-224, Pl. 33 figs. $6-10$.

Sp. No. 46162, found on the bamboo stick in the protected area of Cau Da on August 11, 1965. Two specimens are included; they are respectively $55 \mathrm{~mm}$ long by $27 \mathrm{~mm}$ wide and $55 \mathrm{~mm}$ by $21 \mathrm{~mm}$ wide. The thickness attains to $6 \mathrm{~mm}$ in the former. The branchial siphon is stout and long, attaining to $20 \mathrm{~mm}$ in the latter specimen. The atrial siphon is short and situated with the anterior base of the siphon nearly at the middle of the body. The animal attaches to the substratum by the whole left side. On the right side, the test is sprinkled with a number of papillae all

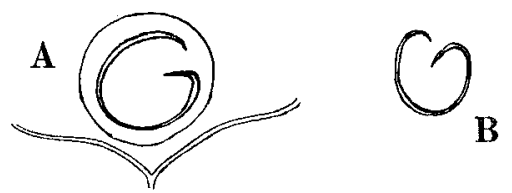

Fig. 4. Ascidia pacifica n. sp. Ciliated grooves of A $-55 \mathrm{~mm}$ long $\times 27 \mathrm{~mm}$ wide specimen and $\mathrm{B}-55 \mathrm{~mm} \times 21 \mathrm{~mm}$ specimen.

over the surface. The musculature of the right side of the mantle body consists of only the transverse muscles which are arranged regularly and widely interrupted at the middle. The anterior end of the intestinal loop reaches anteriorly near the level of the middle of the range between the bases of both apertures. The axis of the second intestinal loop passes the pyloric end of the stomach. The intestine is strongly swollen at the bottom of the second loop. The gonad is fully matured in both specimens. From 90 to 120 tentacles of large and medium orders. The ciliated groove (Fig. 4) is simply horse-shoe shaped, with the right (on the figure) horn incurled. From 40 to 50 inner longitudinal vessels on each side of the branchial sac.

Remarks: The present specimens agree exactly to Ascidia sydneiensis sydneiensis defined provisionally by TокіокA in "Ascidians of Sagami Bay" (1953, pp. 223227). As the type specimen of $A$. sydneiensis is inaccessible at present, and moreover the original description given by StIMPson is very simple, it is very difficult to define 
exactly A. sydneiensis which was first proposed by Strmpson (1855). According to Hartmeyer (Hartmeyer and Michaelsen 1928*, p. 288), the specimen of Ascidia sydneiensis which was identified by STIMPson and sent to Alder in the Hancock Museum in Newcastle was quite identical with Ascidia pyriformis Herdman collected from Port Jackson, Australia. In my opinion, it seems that at least three taxa are included in HARTMEYER's Ascidia sydneiensis defined on that single specimen mentioned above which was regarded by him as the cotype of the species. To make further discussions possible, it is supposed that Stimpson's A. sydneiensis included strictly a single taxon of the three proposed by me. Then, the feature of STImpson's A. sydneiensis can be learned through the description of $A$. pyriformis given by Herdman. The muscles on the right side of the mantle body of $A$. pyriformis is widely interrupted (Herdman 1882**, Pl. 34, fig. 3) and the ciliated groove (Herdman 1882, Pl. 34, fig. 5) is very complicated. These features resemble those of $A$. sydneiensis divisa and $A$. sydneiensis samea. The atrial aperture of $A$. pyriformis is sessile, situated nearly at the middle of the body, and directed posteriorly. According to Stimpson's original description, the "test irregular in shape, thin, often translucent, of a pale purplish color" (STimpson 1855, p. 387). These two points seem to show that $A$. sydneiensis proposed by STImpson resembles $A$. sydneiensis divisa Sluiter more closely than $A$. sydneiensis samea OKA. At present, however, nothing can be referred to as to the situation of the anterior end of the intestinal loop in Herdman's $A$. pyriformis and consequently the conclusive synonymy of StIMPson's Ascidia sydneiensis must be reserved for a future paper. Anyhow, it is evident that A. sydneiensis sydneiensis differs distinctly from STrmpson's A. sydneiensis. The test sprinkled all over the surface with papillae which may grow to minute finger-shaped protuberances or spherical bodies in some specimens, the intestinal loop with its anterior end far beyond the level of the base of the atrial siphon, and the simple ciliated groove even in large individuals are the regular features characteristic to A. sydneiensis sydneiensis. Under the supposition that STIMPson never confused $A$. sydneiensis sydneiensis with other two subspecies provisionally defined by me, A. sydneiensis sydneiensis is better treated as a new species distinct from Stimpson's $A$. sydneiensis, and Ascidia pacifica is proposed here for it.

Loc.: The Palau Islands, the Arafura Sea, Sagami Bay and Nhatrang.

\section{Polyandrocarpa (Eusynstyela) latericius (SLUITER)}

(Text-fig. 5)

A single colony (Sp. No. 46150) was found on August 11, 1965, encrusting the

* Hartmeyer, R. and W. Michaelsen (1928): Ascidiae Diktyobranchiae und Ptychobranchiae. Die Fauna Suidwest-Australiens, Vol. 5, No. 6, pp. 249-460, 61 text-figs.

** Herdman, W.A. (1882): Report on the Tunicata. I. Ascidiae Simplices. Rep. Zool. Challenger Exped., Vol. 6, Part 17, pp. 1-296, 37 pls. 
inner side of an empty oyster shell attached to the bamboo stick in the protected area of Gau Da. The colony is very irregular in outline, but it is larger than $22 \mathrm{~mm} \times$ $16 \mathrm{~mm}$ in extent and includes 15 elliptical zooids up to $7 \mathrm{~mm}$ in length. In smaller zooids, both apertures are situated equally apart from respective body ends. But, in larger ones, the branchial aperture is subterminal, situated nearer to the body end than the atrial aperture is. The common test is hard gelatinous, very thin, translucent and milky white in colour. The test reaches $0.3 \mathrm{~mm}$ thick on large contracted zooids.

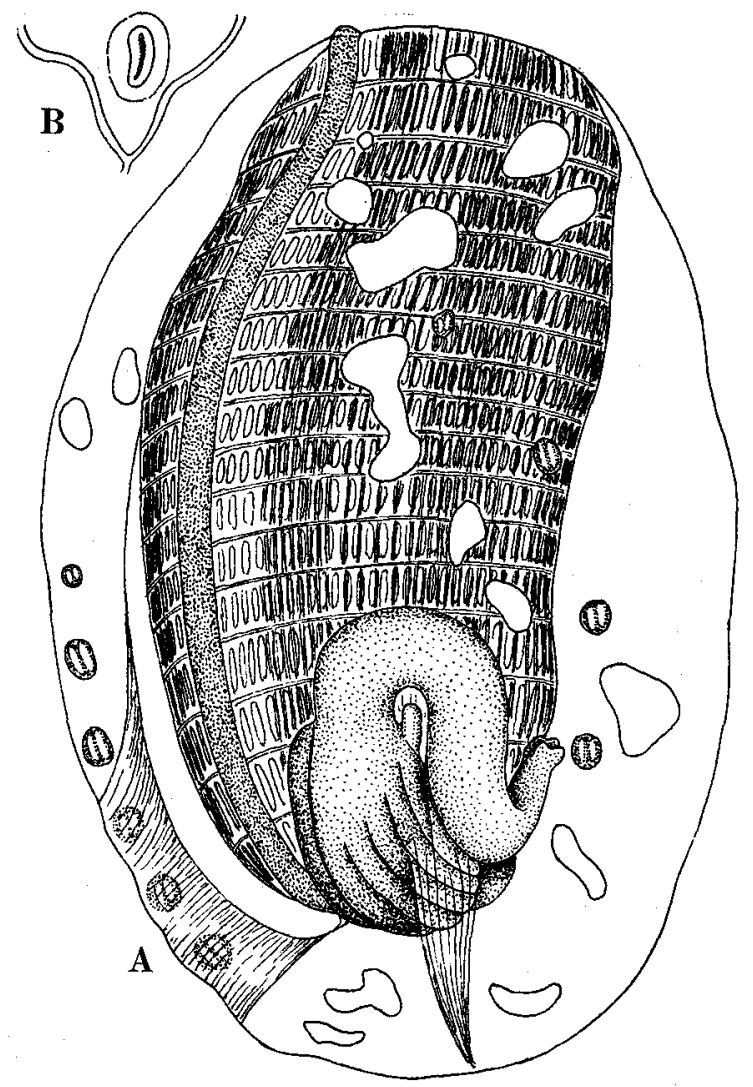

Fig. 5. Polyandrocarpa (Eusynstyela) latericius (SLUTTER). A - Left ventral side of a mantle body, B-Ciliated groove of the same zooid.

It is cartilaginous to leathery in consistency and coloured beautifully rose carmine on the dorsal side of the zooid; both apertures are marked with four radial bands coloured dark red. In larger zooids, the rose carmine colouration around both apertures and adjacent regions fades gradually to yellow brown with the distance from the apertures. The reddish colouration remains along the periphery of the zooid and between both apertures as a pair of colour bands. The surface of the test on zooids is finely wrinkled 
by contraction and sometimes carries a small amount of mud, though it is fully exposed on smaller zooids which are coloured red throughout. The mantle body is yellowish, but reddish around both apertures. The mantle is extremely thin on the ventral side. The branchial aperture is subterminal and the atrial aperture is situated with its anterior base at the middle of the mantle body. The right side is wholly covered with fine transverse muscles. Many endocarps are present on the inner surface of the mantle, especially abundantly on the dorsal side. The atrial velum is furnished with minute tentacles. The loop of the alimentary canal occupies $1 / 3$ to $1 / 2$ of the branchial sac in length. The right ventroposterior part of the branchial sac is supported by a broad mesentery stretching between that part and the mantle wall. Similarly, the bottom of the second intestinal loop is supported by a mesentery issued from the posterior end of the mantle body.

There are 16-17 stigmatal rows on the branchial sac. The inner longitudinal vessels of the branchial sac are arranged in two dissected zooids as follows:

$$
\begin{aligned}
& \begin{array}{l}
\text { Left } \\
\text { Dight }
\end{array} \text { D. } 0(12) 1(6) 1(10) 2(6) 0 \mathrm{~V} . \\
& \text { Left } \quad \text { D. } 0 \quad(8) 1(4) 1(8) 2(7) 2 \mathrm{~V} . \\
& \text { Right }
\end{aligned}
$$

The second plication is less remarkable than others. Probably the fundamental arrangement of the tentacles is 8 large and 8 medium intervened with 16 small. But actually, the arrangement is rather irregular on the dorsal side and the total of the large and medium tentacles scarcely attains beyond 14 . The ciliated groove is a short longitudinal slit (Fig. $5 \mathrm{~B}$ ). The stomach occupies about two thirds of the ventral branch of the first intestinal loop and is provided with about a dozen longitudinal plications on the surface. The pyloric coecum is prominent. The axis of the second intestinal loop passes through the short oesophagus. The anus opens at the level of the transverse vessel between the posterior second and the third stigmatal rows. It is bilobed, and pigmented brownish. One examined zooid has 8 gonads on the left and 2 on the right side, while another zooid has 4 gonads on the left and 6 on the right side. Gonads were immature in all examined zooids. Although the gonads are still immature and the characteristic arrangement of the testes and the ovary cannot be confirmed, the general body structure mentioned above seems enough to make the present identification certain. 